\title{
水晶に依る金屬錯鹽の不齊選擇吸着(第二報) $)^{27}$ 不齊選擇吸着と錯盬の立體配置
}

(昭和十八和四月世六日受颃)

黑 谷 壽 雄 相 見正典 槌田龍太郎

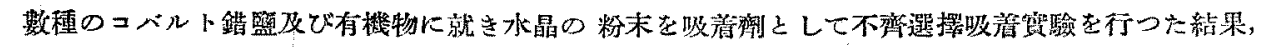

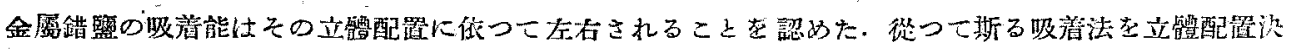
定の一手段として用ることを知つた。

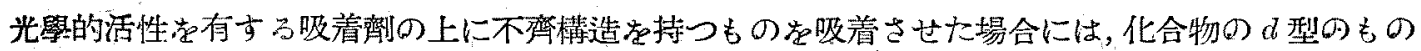
とl型のものとが吸着能を異にして，從つてこ・に不齊選擇吸着を行ふ可能性のあることが考人られ ろのであるが, Willstätter²

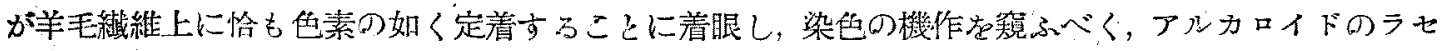
ミ體を样毛に與入てみたのである.然しこの實驗に於ては所期の不齊選擇吸着灰確認し得なかつ

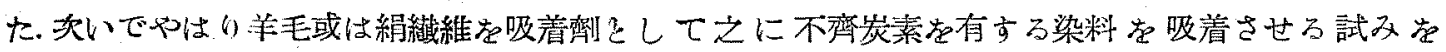
Porter 及び Hirst ${ }^{3)}$, Ingersoll 及び Adams'), Porter 及び Ihrig's), Morgan 及び Skinner ${ }^{6)}$, 更に Brode 及び Adams ${ }^{72}$ が行つてるるが, その中の二,三の場合に於ては,染料の對掌體の一つが他のも のよりも㵶維上に吸着し易いことが判明した. 例へば Ingersoll 及び Adams は, p-アミノベンジー

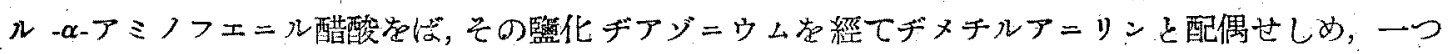
の不齊炭素在持つ染料在造つたが, 原料のフェニルアミノ酛酸が右旋性なる時を左症性なる時々では 染料の吸着率が異ることを示した. 又, Porter 及び Ihrigは て，cb、デル酸より得たものっ方がl 型より造つたものに比して速かに染まること在認めたので あつた.

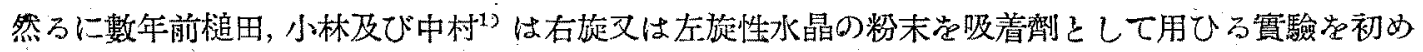
て行U, [Co en $\left.n_{5}\right] \mathrm{Br}_{3},\left[\mathrm{Co} e n_{2} \mathrm{NH}_{3} \mathrm{Cl}_{(2)}^{(1)}\right] \mathrm{Br}_{2},\left[\mathrm{Co} e n_{2} \mathrm{Cl}_{2}(1)\right] \mathrm{Cl},\left[\mathrm{Co}\left\{\mathrm{Co}\left(\mathrm{NH}_{3}\right)_{4}(\mathrm{OH})_{2}\right\}_{3}\right] \mathrm{Cl}_{6}, \mathrm{~K}_{3}[\mathrm{Co}$

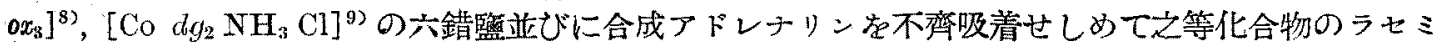
體部分々割方ることに成功した。 そして Stiegmann ${ }^{102}$ は [Pt styrene $\left.\mathrm{Cl}_{2}\right]_{2}$, [Pt stilbene $\left.\mathrm{Cl}_{2}\right]_{2}$ 及び [Co i- $\left.m_{2} \mathrm{CO}_{3}\right]_{2} \mathrm{CO}_{3}$, 又 Karagunis 及び Coumoulos ${ }^{11)}$ は $\left[\mathrm{Cr} e n_{3}\right] \mathrm{Cl}_{3}$ 范, 何れも桘田等に倣つて 分割してるる.

1) 第一報, 棺田, 小林, 中村：本誌, 56(1935), 1339; Bull. Chem. Soc. Japan, 11(1936), 38.

2) Willstätter: Ber., 37(1904), 3758.

3) Porter, Hirst: J.Am. Chem. Soc., 41 (1919), 1264.

4) Ingersoll, Adams: J. Am. Chem. Soc., 44(1922), 2930.

5) Porter, Ihrig: J. Am. Chem. Soc., 45(1923), 1990.

6) Morgan, Skinner: J. Chem. Soc., $127(1925), 1731$.

7) Brode, Adams: J. Am. Chem. Soc., 48(1926), 2193, 2202.

8) $0 x$ 㤌苳根婹

9). $d g$ はヂメチルグリオキシム根

10) C. A. Stiegmann: Dissertation, University of Illinois (1937).

11) Karagunis, Coumoulos: Praktika, 13(1938), 414; Nature, 142(1938), 162. . 


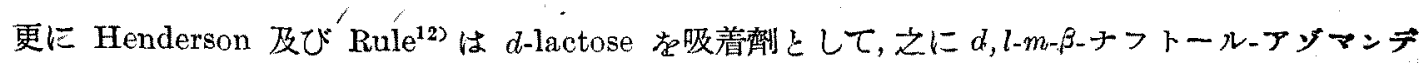
几酸並びに d,l-p-フェニレンデフミンービスーイミノカンフル $\mathrm{C}_{10} \mathrm{H}_{14} \mathrm{O}=\mathrm{N} \longrightarrow . \mathrm{N}=\mathrm{C}_{10} \mathrm{H}_{14} \mathrm{O}$ 及着せしめて之等の分割, 特に後者に於て悰全分割を行ふことが出來た。

以上從來の不齊吸着に關する研究の概要を述べたが, 我タは第一報の方法を踏警して再び吸着實驗 教行つたので, その結累老竝に報告する.

\section{實驗並びに結果}

（I）本實驗に使用した錯監 は $\left[\mathrm{Co} e n_{3}\right] \mathrm{Br}_{3} .3 \mathrm{H}_{2} \mathrm{O},\left[\mathrm{Cr} e n_{3}\right] \mathrm{Cl}_{3 .} .3 .5 \mathrm{H}_{2} \mathrm{O},\left[\mathrm{Co} e n_{2}\left(\mathrm{NO}_{2}\right)_{2}(\mathrm{q})\right] \mathrm{NO}_{3}$, [Co $e n_{9}$ ox] Br, [Co en $\left.{ }_{2} \mathrm{CO}\right]_{3} \mathrm{Cl} . \mathrm{H}_{2} \mathrm{O}, \alpha-\left[\mathrm{Co}(\text { glueine })_{3}\right] \cdot 2 \mathrm{H}_{2} \mathrm{O},\left[\mathrm{Co} e n_{2} \mathrm{NH}_{3} \mathrm{Br}_{(2)}^{(1)}\right] \mathrm{Br}_{2}, 2 \mathrm{H}_{2} \mathrm{O}$, [Co oxin $]^{13)}$ の八種であるが，その中最後の二つ花除くものは方べて裹に迅べた方法"゙で得たものである. [Coen

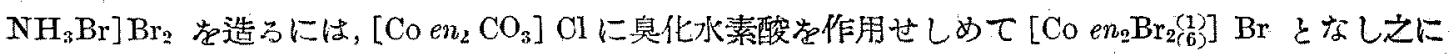

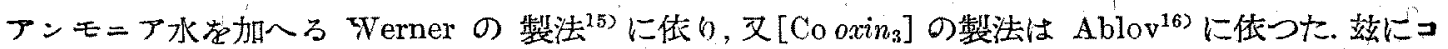

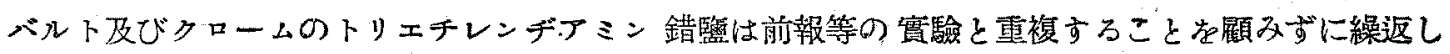
採り舉げたものである. 何, 吸着を行はしむる方法は第一報と全く同じ故說明を省く.

(II) 以前使用したことのある水晶粉末の不齊吸着.

これは錯監の水溶液（[Co oxin $\left.n_{3}\right]$ のみは飽和アルコール溶液）の各 $25 \mathrm{cc}$ に對して, 第一報の實驗 の際使用したことのある右水晶粉末 $1.5 \mathrm{~g}$ 宛與へ，室溫に歺て吸着を行はしめた場合であろ. 吸着 には數時間を費した。その結果は第1表に示す通りで, 部分ふ割が行はれたことがよく認められる.

第 1 表

\begin{tabular}{|c|c|c|c|c|}
\hline 錯 & 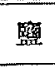 & $\begin{array}{c}\text { 吸着を行はしむる漫度 } \\
(\mathrm{M} / \mathrm{l})\end{array}$ & 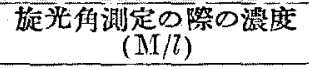 & 旋光旃 (液層 $10 \mathrm{~cm})^{17}$ \\
\hline \multicolumn{2}{|c|}{$\left[\mathrm{Co} e n_{2} \mathrm{CO}_{3}\right] \mathrm{Cl}$} & $1 / 10$ & $1 / 100$ & $+0.04^{\circ}(\mathrm{C})$ \\
\hline \multicolumn{2}{|c|}{ [Co $e n_{2}$ ox $] \mathrm{Br}$} & $1 / 30$ & $1 / 30$ & $+0.04^{\circ}(\mathrm{C})$ \\
\hline \multicolumn{2}{|c|}{$\left.[\mathrm{CoOxin}]_{3}\right]$} & アルコールに飽和 & 餲和溶液を二倍に稀釋 & $+0.04^{\circ}(D)$ \\
\hline \multicolumn{2}{|c|}{$\left[\mathrm{Cr} \quad \mathrm{en}_{3}\right] \mathrm{Cl}_{3}$} & $1 / 100$ & $1 / 100$ & $+0.05^{\circ}(\mathrm{D})$ \\
\hline \multicolumn{2}{|c|}{$\left[\mathrm{Co} e n_{2} \mathrm{NH}_{3 .} \mathrm{Br}\right] \mathrm{Br}_{2}$} & $1 / 200$ & $1 / 200$ & $+0.04^{\circ}(\mathrm{D})$ \\
\hline
\end{tabular}

(III）新しく粉碎した水晶粉末の不䙹吸着.

第 2 '表

\begin{tabular}{|c|c|c|c|}
\hline 監 & $\begin{array}{c}\text { 吸着を行はしむる漂要 } \\
(M / l)\end{array}$ & $\begin{array}{c}\text { 旋光角測定の際の羂应 } \\
(\mathrm{M} / l)\end{array}$ & 郄光解 (液層 $10 \mathrm{~cm}$ ) \\
\hline [Co ens] $\mathrm{Br}_{3}$ & $1 / 100$ & $1 / 100$ & $+0.09^{\circ}(\mathrm{D})$ \\
\hline$\left[\mathrm{Cr} e n_{3}\right] \mathrm{Cl}_{3}$ & $1 / 100$ & $1 / 100$ & $+0.08^{\circ}(\mathrm{D})$ \\
\hline$\left[\mathrm{Co} \quad \mathrm{en}_{2} \mathrm{NH}_{3} \cdot \mathrm{Br}\right] \mathrm{Br}_{2}$ & $1 / 100$ & $1 / 400$ & $+0.02^{\circ}(\mathrm{C})$ \\
\hline$\left[\mathrm{Co} e n_{2}\left(\mathrm{NO}_{2}\right)_{2}\right] \mathrm{NO}_{3}$ & $1 / 100$ & $1 / 100$ & $+0.04^{\circ}(\mathrm{D})$ \\
\hline$\left[\begin{array}{lll}\mathrm{Co} & e n_{2} & \mathrm{CO}_{3}\end{array}\right] \mathrm{Cl}$ & $1 / 200$ & $1 / 200$ & $+0.03^{\circ}(\mathrm{C})$ \\
\hline$\left[\begin{array}{lll}\mathrm{Co} & \mathrm{en} n_{2} & \mathrm{ox}\end{array}\right] \mathrm{Br}$ & $1 / 100$ & $1 / 100$ & $+0.03^{\circ}(\mathrm{C})$ \\
\hline$\alpha-\left[\mathrm{Co}(\text { glycine })_{3}\right)$ & $1 / 100$ & $1 / 100$ & - \\
\hline
\end{tabular}

12) Henderson, Rule: Nature, 141(1938), 917; J. Chem. Soc., 1939, 1568.

13) oxin は 8-オキシキノリン.

14) 黑谷, 槌田：Bull. Chem. Soc. Japan, 15(1940), 427 .

15) Werner, Scholze: Ber., 44(1911), 1893.

16) Ablov: Bull. soc. chim., 53(1933), 234.

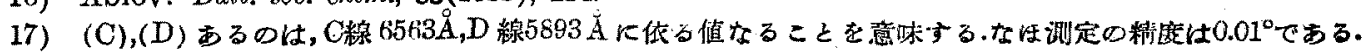


右水晶を粉碎し，乳鉢で磨り潰してよく水洗した後乾燥せるもの1 g 宛を，各錯監の水溶液 $25 \mathrm{cc} に$ 對して使用した所，第 2 表の如き結果な得た．侣オキシン 錯監は水に溶けないのでこの實驗には除外 Lた.

(IV) d,l-マンデル酸の不齊㚫着.

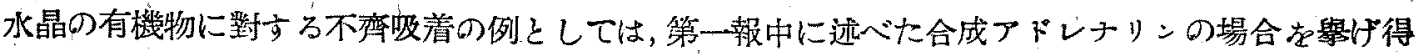
ろが更に他のものに就ても同樣の實驗を行つた所，マンデル酸に於てのみ良い結果在得た，惯驗に供

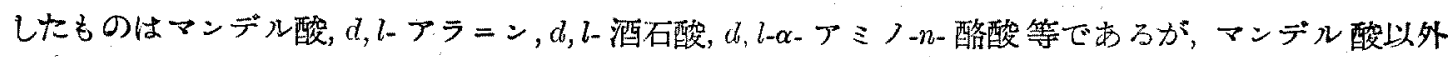
のもの旋光能はこのものに較べると弱いので, 不齊吸着が行はれてるてもこの結果官測り得なかつ たかも知れない,d,bマンデル酸ばベンツアルデヒドより合成しベンジール及び氷にて再結晶. 之を

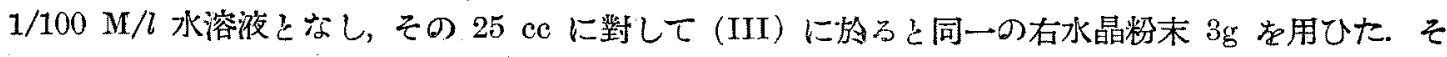
の結果澓愿 $20 \mathrm{~cm}$ に於て $a_{\mathrm{D}}=+0.04^{\circ}$ 得た. 但し测定濃度はやは $1 / 100 \mathrm{M} / l$ である.

\section{結果の考察}

不齊化合物の立體配置に關する砰究中錯監の分野でば從來三通りの決定法が知られてるろ. 即ち

(1)，部分犃體異性軆 (diastereomer) の溶解度に依る Werner 法 $^{18)}$,

(2) 結晶の isomorphism に依乃 Jaeger ${ }^{192}$, Delépine 法 ${ }^{20)}$,(3)光學的性質に依乃 Kuhn?1) 法がそ れであるが22，今第一報中で述べた所の「同一型の不齊吸着劑に吸着される，或は吸着され易いもの は相對的に同じ立觶配置る有する」と云ふ假說の正しいことが分れば，更に第四の方法が得られるこ とになる。

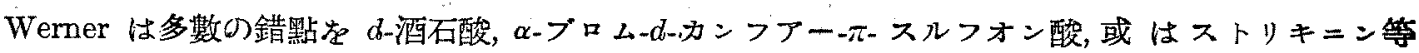
を用ひて光學的異性體に分割した. 第 3 表中には，之等分割劑と結合して臨となつた際溶解度が小

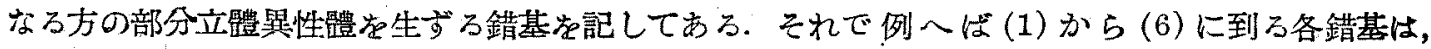

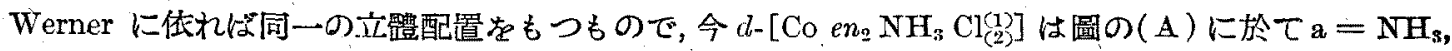
b=Cl であるとすれば（B）は，型となる譯であり，更に(A)

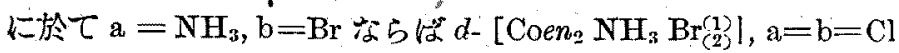
ならば $l$ [Coen $\left.2 \mathrm{Cl}_{2(2)}^{(2)}\right]$, となるのである。

次に之等錯基の有方万吸收带の長波長側に於万圆偏光二色 性の正負, 郎ち Cotton 效果の符號存 Kuhn 並びに Mathieu ${ }^{23)}$ の實驗結果から求めると表の第三行目に記方通りであるが，

Kuhn によれば同符號のものは同じ立體配置をもつべきであ

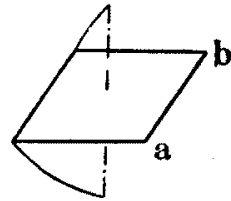

(A)

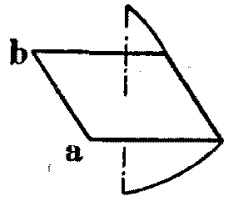

(B)

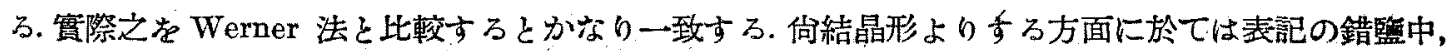

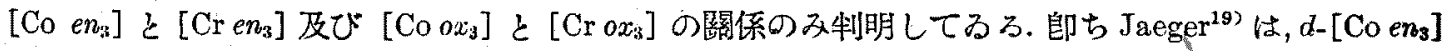

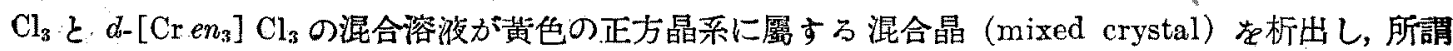

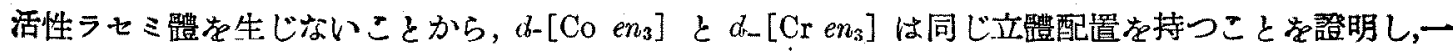

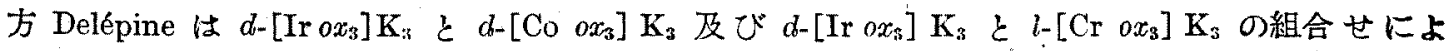

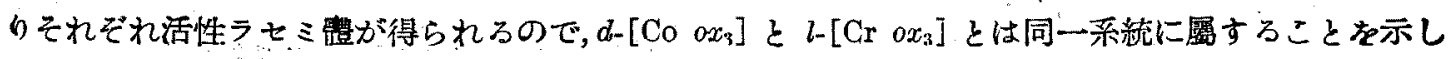

18) Werner: Ber, 45(1912), 1229.

19) Jaeger: Bull. soc. chim., 4(1937), 1201.

20) Delépine: Bull. soc. chim., 1(1934), 1256; Helv. Chim. Acta, 22(1939), 519.

21) Kuhn, Bein: Z. anorg. allgem. Chem., 216(1934), 321; Naturvissenschaften, 26(1938), $289,305$.

22) 北上敏; “錯暨” 182 頁 (昭和 16).

23) Mathieu: Bull. soc. chim., 3(1936), 463; J. chim. phys., 33(1936), 78 . 
たのである.

それで, 以上の錯基をもつ錯監の右水晶に對方る吸着狀海を前啹の結果と仿せ檢し，第 3 表中に記

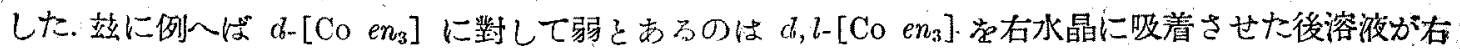
旋性を示すのであるから，d型のものはl型よりも弱く吸着されることとなると云ふ意味である。表中 [Co en. $\left.\mathrm{NH}_{3} \mathrm{Cl}_{(2)}^{(1)}\right]$ を除けば他の方法に依る結果とよく一致してるるこにが見られる.

第 3 表 ${ }^{24}$

\begin{tabular}{|c|c|c|c|c|c|}
\hline 1 & 基 & 部分立澧翼性䯣の溶解度 & Cotton 効果 & 絬 晶 & 右水晶の吸䔔能 \\
\hline 1 & $d-\left[\mathrm{Co}\right.$ en: $\left.2\left(\mathrm{NH}_{3}\right)_{2}(2)\right]$ & 小) & + & & - \\
\hline 2 & 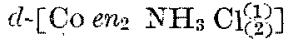 & $"$ & 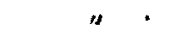 & & 强 \\
\hline 3 & $d-\left[\mathrm{Co} e n_{2} \mathrm{NH}_{3} \mathrm{Br}_{(2)}^{(1)}\right]$ & (-BCS25). & $"$ & & 弱 \\
\hline 4 & $d-\left[\begin{array}{lll}\mathrm{Co} & \mathrm{en} & \left(\mathrm{NO}_{2}\right)_{2}(2)\end{array}\right]$ & $a-b\left(b^{-1}\right.$ & $n$ & & $"$ \\
\hline 5 & $l-\left[\mathrm{Co} e n_{2} \mathrm{Cl}_{2(2 ;}^{(1)}\right]$ & $"$ & $? '$ & & $"$ \\
\hline 6 & $l-\left[\mathrm{Co} e n_{2} \mathrm{NH}_{3} \mathrm{NO}_{2(2, j]}^{(1)}\right]$ & $n$ & - & & - \\
\hline 7 & $d=\left[\begin{array}{lll}\mathrm{Co} e n_{2} & \mathrm{CO}_{3}\end{array}\right]$ & - & + & & 弱 \\
\hline 8 & $d-\left[\begin{array}{lll}\mathrm{Co} & \mathrm{e} n_{2} & \mathrm{ox}\end{array}\right]$ & - & $"$ & & $"$ \\
\hline 9 & $d-\left[\begin{array}{ll}\mathrm{Co} & e n_{3}\end{array}\right]$ & 小 & " & 网 & " \\
\hline 10 & $d-\left[\begin{array}{ll}\mathrm{Cr} & e n_{3}\end{array}\right]$ & $"\}^{\mathrm{x} d-\operatorname{Tart}^{-10}}$ & $"$ & 同访 & $"$ \\
\hline 11 & 7- $-\left[\begin{array}{cc}\mathrm{Co} & 0 x_{3}\end{array}\right]$ & 小 $\zeta_{\mathrm{a}+\mathrm{man}}$ & $"$ & 人 & $"$ \\
\hline 12 & $d-\left[\begin{array}{ccc}\mathrm{Cr} & 0 x_{3}\end{array}\right]$ & " $\operatorname{Strych}^{2 i}$ & $"$ & \} 问形 & - \\
\hline
\end{tabular}

一方アドレナリンにマンデル酸に就いて考察するに,(一)-マンデル酸を(ー)ーアドレナリンとは水 酸基の部分に於て同一の配置告なしてるると云は和る283

$$
\begin{aligned}
& \mathrm{COOH} \\
& \mathrm{HC}-\mathrm{OH} \\
& \mathrm{C}_{6} \mathrm{H}_{5} \\
& \mathrm{H}_{2} \mathrm{C}-\mathrm{NH}-\mathrm{CH}_{3} \\
& \mathrm{HC}-\mathrm{OH} \\
& \dot{\mathrm{C}}_{6} \mathrm{H}_{3}(\mathrm{OH})_{2} \\
& d(-) \text {-マンデル酸 } \\
& \text { (一)-アドレナリン }
\end{aligned}
$$

そして右水晶の吸着能を檢出するに, 何れに於ても方旋性のものに對して强いのであるから，この 結果も亦前記の假說发支持方る.

以上のことから活性水晶の吸着の强弱は化合物の立體配置に左右せら秃るこを，從つて不齊吸着法

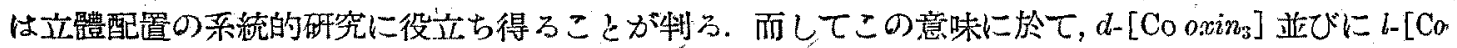
$\left.d g_{2} \mathrm{NH}_{3} \mathrm{Cl}\right]$ (C線) は第3 表中の諸酷基と同一型に屬するものと解せられるのであろが, 倘この他 の試料に就ても實驗を續行中である。

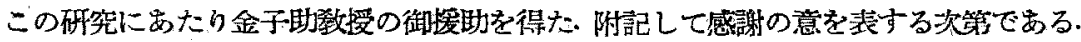

(大阪帝國大學理學部化學倿宰)

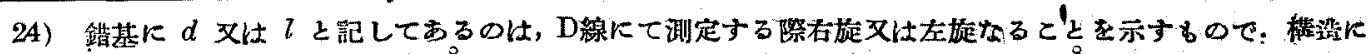

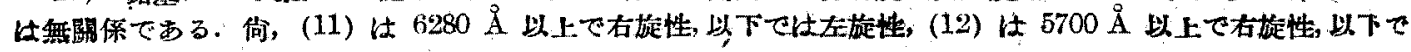

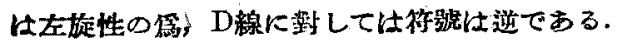

25) $\alpha$ ープロムーdーカンファーースルサオン酸盟

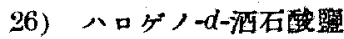

27) トリストリキニン盃

28) Freudenberg: “Stereochemie”, S. 697, Leipzig (1933). 